\title{
The method of modified RFM-analysis as a tool to ensure economic sustainability
}

\author{
Vladislav Shchekoldin*, Oleg Lobach, and Konstantin Mokrousov \\ Novosibirsk State Technical University, K. Marx Avenue, 20, 630073 Novosibirsk, Russia
}

\begin{abstract}
In the process of development of society, the problem of sustainable development has always been relevant for any subject of the economy. It affects areas such as social progress, economic development and environmental responsibility. In addition, sustainable development is directly related to the macro and micro level of the economy of any country. In this regard, it is necessary to analyze the current situation to meet this need. The article presents the MRFM-analysis method. It includes segmentation of customers who have made at least one purchase. This approach is based on classic RFM-analysis. According to the method, the segmentation of Zenit LLC clients for 2019 and 2020 was carried out, the clusters were characterized and recommendations were given for further work with each cluster.
\end{abstract}

\section{Introduction}

Today it is impossible to imagine the existence of life without a system. After all, system allows its subjects to determine their place in it and act harmoniously to achieve a common goal. It was thanks to systems that communities of the first people were able to overcome time and form the first states.

One of the most important capabilities of any system is homeostasis. This term refers to the ability of the system to maintain the constancy of its internal state through coordinated actions aimed at maintaining dynamic balance. In other words, this means that the system is capable of self-regulation of its internal processes. For example, in biology, this process allows a population of any species to exist as long as possible through the appearance of new individuals. Something similar is happening with economic systems, only now instead of homeostasis the term «sustainable development» appears. In this case, it refers to the process of economic and social change in which natural resources, investment direction, scientific and technological development orientation, personality development and institutional change are consistent with each other and strengthen the current and future potential to meet human needs and aspirations. The United Nations (UN) pays significant attention to sustainable development issues. On organization's official website, within the framework of this issue the following goals are set [1]:

1. Eradication of poverty;

2. Elimination of hunger;

\footnotetext{
*Corresponding author: schekoldin@corp.nstu.ru
} 
3. Good health and wellbeing;

4. Quality education;

5. Gender equality;

6. Clean water and sanitation and others.

This topic is considered not only at the level of states, but also at the level of enterprises, since for them stable economic development is the key to a long and successful existence. After all, it is by attracting more customers that the likelihood of the company's survival in the market increases. To increase customer loyalty, it is necessary to carry out certain activities such as the creation of personal offers, an individual approach, etc. But at the same time, one cannot work with all clients in the same way. It is necessary to segment them to develop activities for each selected cluster $[2,3,4]$. One of the methods to help segment customers is RFM-analysis [5].

\section{Materials and Methods}

Many consumer research methods focus on analyzing their behavioral characteristics. These include: motives for making a purchase, reaction to a product, brand loyalty, etc. In addition, assessments of the attractiveness of a product or a service are carried out against the competitors.

In recent years, there has been an increase in the number of studies that use RFM-analysis as a segmentation method $[5,6]$. One of its features is that only those customers who have made at least one purchase within a certain period of time are counted. Most often, this method uses the following indicators to describe the behavior of buyers $[6,7]$ :

- recency - the period of time that has passed since the last purchase. In the course of the analysis, much attention is paid to the empirical property of this indicator. Depending on how much time has passed since the last purchase, the likelihood of a repeat purchase will change. These values are inversely proportional.

- frequency - a set of actions that were committed by the client during the analyzed period of time. Unlike the previous indicator, the frequency of previous purchases and the likelihood of future purchases are directly proportional. Sometimes this indicator is replaced by others that are better suited for analyzing a particular situation.

- monetary - the total amount of money spent by the client during the investigated period of time. Like the frequency of purchases, this indicator is directly proportional to the likelihood of making a future purchase.

The methodology for conducting RFM-analysis is based on the fact that it is necessary to distribute clients into five groups of equal size [8]. Depending on the indicator, the approach to customer segmentation will change. So, for the $\mathrm{R}$ indicator, one needs to sort customers in ascending order, that is, from those who made a purchase recently to those who made a purchase a very long time ago. In this list, recent customers receive the code "5", and the oldest - "1". And for indicators F and M, sorting by decreasing indicators is used.

As a result, a three-dimensional matrix is formed. In it, each customer has their own code, ranging from code "111" (non-valuable customer) to code "555" (most valuable customer).

Unfortunately, this method has a drawback. It lies in the fact that due to the need to divide clients into equal groups, some of them can be "randomly" assigned to different groups, although they have very similar indicators.

To solve this problem, a modified RFM-analysis technique (hereinafter referred to as MRFM-analysis) was proposed earlier [6,9]. It is based on the use of the cumulative curves' apparatus. This methodology allows one to classify consumers for each indicator according to the same pattern. 
It is important to note that for the correct application of the method, the R values must be converted to reciprocals. This is necessary in order for a shorter purchase period to correspond to a larger value of the indicator and, accordingly, vice versa. For indicators $\mathrm{F}$ and $\mathrm{M}$, such a transformation is not necessary, since initially the largest purchase amount or a larger number of purchases corresponds to a larger value of the indicators.

\section{Results and Discussion}

To demonstrate the capabilities of the described method, the clients of Zenit LLC were analyzed. The studied organization is engaged in the wholesale of packaging materials for finished food products in the city of Novosibirsk. The target segment of this company includes legal entities engaged in the production and (or) sale of finished food products located within the city of Novosibirsk. Sales data for 2019 and 2020 were taken as an information base.

According to the methodology for conducting the MRFM-analysis given above, the segmentation of the company's clients was carried out for 2 years, presented in Table 1.

Table 1. Results of MRFM-analysis for 2019 and 2020

\begin{tabular}{|c|c|c|c|c|c|}
\hline \multicolumn{3}{|c|}{2019} & \multicolumn{3}{|c|}{2020} \\
\hline № & Cluster name & $\begin{array}{l}\text { Number of } \\
\text { companies }\end{array}$ & № & Cluster name & $\begin{array}{l}\text { Number of } \\
\text { companies }\end{array}$ \\
\hline 1 & «One-time Clients» & 15 & 1 & «One-time Clients» & 12 \\
\hline 2 & «Irregular buyers» & 7 & 2 & «Irregular buyers» & 6 \\
\hline 3 & «Newbies» & 3 & 3 & «Newbies» & 5 \\
\hline \multirow{2}{*}{4} & \multirow{2}{*}{ «Regular buyers» } & \multirow{2}{*}{9} & 4 & «Regular buyers» & 6 \\
\hline & & & 5 & «VIP» & 7 \\
\hline
\end{tabular}

According to this table, the following conclusions can be drawn:

a. there was an increase in the number of clusters in 2020. The reason for this was the more accurate results of cluster analysis. Companies have grouped themselves into clusters this year more accurately than in 2019.

b. the number of «One-time clients» has decreased. But despite this, the share of these companies in the total number of all buyers takes the first place. The management of the company is committed to creating long-term relationships with its customers, so «One-time customers» are not given special attention.

c. depending on the availability of outlets and the scale of production, companies are well segmented into clusters, the more production and outlets a company has, the higher it is in the cluster rating.

d. the rest of the companies were divided into clusters approximately equally.

e. several companies in 2019 did not make purchases in 2020. Thus, 11 companies left: 1 from the «Regular customers» cluster, 1 from the «Irregular customers» cluster and 9 companies from the «One-time customers» cluster.

Next, the tendency of changes in clusters over 2 years was studied (see Table 2). Companies that have retained their cluster are shown in gray. 
Table 2. Trend of clusters

\begin{tabular}{|c|l|c|c|c|c|c|}
\hline \multicolumn{2}{|c|}{ Jump table } & \multicolumn{5}{|c|}{2020} \\
\cline { 3 - 7 } & Cluster 1 & Cluster 2 & Cluster 3 & Cluster 4 & Cluster 5 \\
\hline \multirow{3}{*}{2019} & Cluster 1 & 5 & 1 & - & - & - \\
\cline { 2 - 7 } & Cluster 2 & 2 & 4 & - & - & - \\
\cline { 2 - 7 } & Cluster 3 & - & - & - & 2 & 1 \\
\cline { 2 - 7 } & Cluster 4 & - & - & - & 3 & 5 \\
\hline
\end{tabular}

According to table 2, we can conclude that 12 companies that have retained their cluster. Most of these companies are in the "disposable clients" cluster. Most likely, there are still companies operating in the same industry as Zenit LLC. They sometimes buy a product that they cannot find from their suppliers. It is noticeable that in 2020 there is no one left in the "newcomers" cluster. This justifies the name of the cluster and its characteristics. Quite a lot of clients (5 companies) got into the new fifth cluster "VIP", which indicates their desire to work with the studied company.

\section{Conclusions}

Analyzing the company's customers and identifying clusters is just the beginning. It is also necessary to develop a plan for proper interaction with each cluster to maximize profits.

The VIP cluster includes the most loyal customers. They are ready to buy our products even without additional marketing campaigns. For them it is worth developing the best service (personal manager, bonus programs) or providing valuable gifts on some occasions. These activities will further increase customer loyalty in favor of the company.

The «Regular buyers» cluster contains growing customers. They have already met our company, but they do not have high loyalty. It is very important to research their values and interests in order to plan future events to increase loyalty. Developing personalized offers will be a great way to increase client loyalty to our company.

The «Newbies» cluster includes companies that have just started working with Zenit LLC. It remains to be seen how further cooperation will develop. It is necessary to collect information about their values, interests in order to understand with whom it will most likely be possible to create strong and long-term relationships. Since such customers can become "one-off", it is necessary to get the maximum revenue from the deal with them through additional sales.

Some companies that got into the «Irregular buyers» cluster could previously be in «VIP» or «Regular buyers». They can be very valuable to the company. It is necessary to find out why they left, get feedback and fix the problems. These could be excessively high prices, low range of products and other reasons. The rest of the companies in this cluster should be treated like «Newbies».

The rest of the companies are included in the «One-time clients» cluster. These customers made very few purchases with very little value. In the process of searching for the right product, they accidentally found out about Zenit LLC and became their clients. The likelihood of repurchasing such customers is very low. In order to try to get them back, one can offer some discounts and promotions. The majority will most likely refuse, but someone can go back and move to another more profitable cluster.

Improving analytical methods enables companies to operate more efficiently and at the lowest cost. Accurate customer segmentation allows entrepreneurs to create the best deals for their target segment with increasing of their loyalty and their profits. Thus, the sustainable economic development of the company could be achieved this way. 


\section{References}

1. Sustainable development goals (2021) https://www.un.org/

2. P.S. Fader, B.G. Hardie, K.L. Lee, Journal of Marketing Research, 42(4) (2005)

3. W. Reinartz, V. Kumar, Harvard Business Review (2002)

4. A.M. Hughes, Marketing Tools, 5 (1996)

5. J.-T. Wei, S.-Y. Lin, H.-H. Wu, African Journal of Business Management, 4(19) (2010)

6. M.E. Tsoy, V.Y. Shchekoldin, $14^{\text {th }}$ International Scientific-Technical Conference on Actual Problems of Electronic Instrument Engineering, APEIE 2018-Proceedings, 443 (2018)

7. M.E. Tsoy, V.Y. Shchekoldin, M.N. Lezhnina, Russian Journal of Entrepreneurship, 18(21), 3113 (2017)

8. J.R. Miglautsch, Database Marketing, 8(1), (2000)

9. V.Y. Shchekoldin, N.A. Titova, Practical Marketing, 218(4) (2015) 